\title{
The distribution of potential West Nile virus vectors, Culex pipiens pipiens and Culex pipiens quinquefasciatus (Diptera: Culicidae), in Mexico City
}

Alvaro Diaz-Badillo ${ }^{1,5}$, Bethany G Bolling², Gerardo Perez-Ramirez', Chester G Moore², Jorge P Martinez-Munoz³, America A Padilla-Viveros ${ }^{4}$, Minerva Camacho-Nuez ${ }^{5}$, Alfonso Diaz-Perez ${ }^{6}$, Barry J Beaty ${ }^{2}$ and Maria de Lourdes Munoz ${ }^{1 *}$

\begin{abstract}
Background: Culex spp. mosquitoes are considered to be the most important vectors of West Nile virus (WNV) detected in at least 34 species of mosquitoes in the United States. In North America, Culex pipiens pipiens, Culex pipiens quinquefasciatus, and Culex tarsalis are all competent vectors of WNV, which is considered to be enzootic in the United States and has also been detected in equines and birds in many states of Mexico and in humans in Nuevo Leon. There is potential for WNV to be introduced into Mexico City by various means including infected mosquitoes on airplanes, migrating birds, ground transportation and infected humans. Little is known of the geographic distribution of Culex pipiens complex mosquitoes and hybrids in Mexico City. Culex pipiens pipiens preferentially feed on avian hosts; Culex pipiens quinquefasciatus have historically been considered to prefer mammalian hosts; and hybrids of these two species could theoretically serve as bridge vectors to transmit WNV from avian hosts to humans and other mammalian hosts. In order to address the potential of WNV being introduced into Mexico City, we have determined the identity and spatial distribution of Culex pipiens complex mosquitoes and their hybrids.
\end{abstract}

Results: Mosquito larvae collected from 103 sites throughout Mexico City during 2004-2005 were identified as Culex, Culiseta or Ochlerotatus by morphological analysis. Within the genus Culex, specimens were further identified as Culex tarsalis or as belonging to the Culex pipiens complex. Members of the Culex pipiens complex were separated by measuring the ratio of the dorsal and ventral arms (DV/D ratio) of the male genitalia and also by using diagnostic primers designed for the Ace.2 gene. Culex pipiens quinquefasciatus was the most abundant form collected.

Conclusions: Important WNV vectors species, $C$. p. pipiens, $C$. p. quinquefasciatus and $C X$. tarsalis, are all present in Mexico City. Hybrids of $C x . p$. pipiens and $C x$. p. quinquefasciatus were also collected and identified. The presence and abundance of these WNV competent vectors is a cause for concern. Understanding the distribution of these vectors can help improve viral surveillance activities and mosquito control efforts in Mexico City.

\section{Background}

Arthropod-borne viral (arboviral) infections are a major public health concern, causing considerable morbidity and mortality in humans and livestock throughout the world. There are more than 100 arboviruses that cause disease in humans, including members of the

\footnotetext{
* Correspondence: Imunoz@cinvestav.mx

'Department of Genetics and Molecular Biology, Centro de Investigación y de Estudios Avanzados del Instituto Politécnico Nacional, Ave. Instituto Politécnico Nacional No. 2508, San Pedro Zacatenco-Gustavo A. Madero, México D.F., C.P. 07360, México

Full list of author information is available at the end of the article
}

Flaviviridae, Bunyaviridae, and Togaviridae families [1]. Arboviral infections produce a broad spectrum of disease, ranging from asymptomatic infection to mild febrile illness or more severe conditions, such as encephalitis or hemorrhagic fever, which may result in long-term sequelae or death [2,3]. Human and animal pathogenic arboviruses such as West Nile virus (WNV), Chikungunya virus (CHIKV), Rift Valley fever virus (RVFV) and Bluetongue virus (BTV) have emerged and caused epidemics in North America, Europe and the Arabian Peninsula [1]. Culex are important vectors of West Nile virus and other arboviruses [2,3] in North

\section{Biomed Central}


America, and consequently prediction and monitoring of their abundance are central to arboviral surveillance and control programs.

West Nile virus (WNV) was first isolated in America from Culex mosquitoes and birds in New York City in 1999. Subsequently, the virus has spread westward across the country with the total numbers of reported cases exceeding 30,000 and more than 1200 fatalities occurring in the past 12 years [4]. WNV is maintained in nature by a bird-mosquito transmission cycle $[5,6]$. The most important mosquito vectors belong to the genus Culex, a very closely related group of mosquitoes originating in Africa [7,8]. Culex spp. mosquitoes are widespread and can be found in tropical and temperate climate zones on all continents except Antarctica [9].

$C x$. p. pipiens, $C x . p$. quinquefasciatus, and $C x$. tarsalis are considered to be the primary vectors of WNV in North America for several reasons. First, they are the most common mosquitoes in urban areas [10-14]; WNV outbreaks typically occur during the peak abundance period of these vector species [15]; they are competent laboratory vectors of WNV [16]; and they have repeatedly been found infected with WNV in nature in the United States [17]. Unlike most other arboviruses, WNV has been detected in several genera and numerous species of mosquitoes, including 60 North American species and over 75 species from more than 10 genera worldwide [18]. Culex pipiens complex mosquitoes also serve as important vectors of St Louis encephalitis [19], Rift Valley fever [20] and Japanese encephalitis viruses [21].

The global distribution of the Cx. p. pipiens, Cx. $p$. quinquefasciatus and the North American distribution of $C x$. tarsalis poses a threat for introduction and transmission of WNV into Mexico including Mexico City. Culex spp. mosquitoes are frequently detected on airplanes [22,23], and the international airport in Mexico City receives numerous flights from WNV endemic areas daily. WNV was introduced into Northern Mexico from the central United States in 2002, presumably via migration of viremic birds [24]. Either of these mechanisms could result in the introduction of WNV into the metropolitan area of Mexico City. The presence of a susceptible human population, approximately 20 million people, and abundant $C x$. pipiens complex mosquitoes is of great public health concern.

The Cx. pipiens complex mosquitoes in Europe differ in behavior and physiology compare to the American mosquitoes and there is little evidence of gene flow between species [16]. Cx. p. pipiens have been implicated in urban outbreaks of WNV in Europe; however these outbreaks were nonrecurring and localized [16], whereas in the United States WNV is enzootic and widespread outbreaks occur. Interestingly, hybrids between $C x . p$. pipiens and $C x . p$. quinquefasciatus are widely found in the United States [16]. These hybrids, which presumably feed on birds as well as humans, may contribute to the sustained transmission of WNV to humans and horses in North America.

Because of their potential importance in serving as bridge vectors for WNV from avians to humans, we were interested in determining the frequency and distribution of $C x . p$. pipiens-Cx. p. quinquefasciatus hybrids in Mexico City.

The Cx. pipiens complex is considered a controversial topic in mosquito taxonomy [25], because divergent physiological and behavioral traits occur without distinctive morphological differentiation. Two methods used to distinguish between $C x . p$. pipiens and $C x . p$. quinquefasciatus are: 1) DV/D ratio, and 2) PCR amplification of acetylcholinesterase (Ace.2) gene sequences. The DV/ $\mathrm{D}$ ratio refers to the relative overlap and measurement of the dorsal and ventral arms in male genitalia. DV/D ratios for $C x . p$. pipiens are less than 0.2 , for $C x . p$. quinquefasciatus they are greater than 0.4 , and hybrids have intermediate ratios between 0.2-0.4 [26,27]. PCR amplification of Ace. 2 gene sequences result in amplicons of different sizes specific for the two taxa [28-30].

In this study, mosquitoes were differentiated by both the male DV/D ratio measurements and by the Ace. 2 gene PCR product analysis [30]. Mosquito larvae were collected from breeding sites, reared to adults, and DV/ $\mathrm{D}$ ratios were determined in males. Morphological and molecular results were used to determine whether the mosquito was $C x$. p. quinquefasciatus, $C x$. $p$. pipiens or a hybrid between the two species.

Determining the distribution of $C x . p$. pipiens, $C x . p$. quinquefasciatus, their hybrids and $C x$. tarsalis is necessary to determine the epidemic potential of WNV in Mexico City. This information will provide base-line information for initiating surveillance programs and initiating control activities in the event that WNV is introduced into the region.

\section{Methods}

\section{Study area}

Mexico City, the capital city of Mexico, is a Federal District. The Distrito Federal is at the same administrative level as the states. It is located in the Valley of Mexico, also called the Basin of Mexico or the Valley of Anáhuac, a large valley located in the Trans-Mexican Volcanic Belt in the high plateaus at the center of Mexico. It has a minimum elevation of 2,200 meters above sea level and is surrounded by mountains and volcanoes that reach elevations of over 5,000 meters. The city primarily rests on what was once Lake Texcoco. The entire lakebed is now paved over and most of the city's remaining forested areas lie in the southern boroughs of 
Milpa Alta, Tlalpan and Xochimilco. The city has a temperate highland climate [31], due to its tropical location and high elevation. The lower region of the valley receives less rainfall than the higher regions of the south. The lower boroughs of Iztapalapa, Iztacalco, Venustiano Carranza and the west portion of Gustavo A. Madero are usually drier and warmer than the upper southern boroughs of Tlalpan and Milpa Alta, a mountainous region of pine and oak trees known as the range of Ajusco, Tlalpan. Seasonally, the lowest temperatures usually register during January and February, reaching -2 to $-5^{\circ} \mathrm{C}\left(28\right.$ to $\left.23^{\circ} \mathrm{F}\right)$, sometimes accompanied by snow showers on the southern regions of Ajusco. The maximum temperatures occur during late spring and summer reaching up to $32^{\circ} \mathrm{C}\left(90^{\circ} \mathrm{F}\right)$. The area receives about $700 \mathrm{~mm}$ of annual rainfall, which is concentrated from June through September/October with little or no precipitation the remainder of the year. Mexico City is a prominent economic, industrial, and cultural center in the country and is the most populous city with over $8,836,045$ inhabitants in 2008 [32]. The Federal District is divided into 16 districts or boroughs. The boroughs are composed of hundreds of neighborhoods [33]. The metropolitan area, Zona metropolitana del Valle de México, consists of the Federal District and 60 other municipalities, mainly located north and east of Mexico City. This area has a total population of approximately 20,000,000 inhabitants (2010 estimate, 29).

\section{Mosquito collection and identification}

Mosquitoes were collected as larvae aboveground from various urban (Figure 1A), suburban (Figure 1B) and rural cemeteries (Figure 1C) in Mexico City during 2004-2005. This represents the first study describing mosquito larval habitats in Mexico City. Larvae were collected from tree holes, ditches, decorative ponds, flower pots, buckets, and water-retaining debris from each cemetery (Figure 1D-I). The water in the collection sites was present for different periods of time. Temporal analysis of mosquito population dynamics was addressed by performing monthly collections on six occasions from May through October 2005. Larvae were carried alive to the insectary where they were reared to adults and examined after emergence. Larvae were reared under standard conditions and pupae were placed (approximately 200 pupae/cup) in cages $(30 \times 30 \times 30$ $\mathrm{cm}$ ) for adult emergence (approximately 400 adults/ cage). Mosquitoes were maintained at $28^{\circ} \mathrm{C} \pm 2^{\circ} \mathrm{C}$ and photoperiod of 14:10 (L:D) h.

Specimens were identified to species with the aid of a stereomicroscope by using standard identification keys and recently described characters [34] including the DV/D ratio descriptive key [35]. Culex pipiens complex specimens were further subjected to a species-specific polymerase chain reaction (PCR) test based on ribosomal DNA (Ace.2 gene) to confirm the results of morphologic identifications $[30,34]$. Identified specimens were either processed immediately for genomic DNA extraction or stored at $-80^{\circ} \mathrm{C}$.

\section{Genomic DNA extraction}

Genomic DNA extraction was performed on individual male mosquitoes. Each mosquito was homogenized with the aid of a microtube pestle (USA Scientific, Enfield, $\mathrm{CT}$ ) in a $1.5 \mathrm{ml}$ tube containing $180 \mu \mathrm{l}$ phosphate buffered saline (PBS, $137 \mathrm{mM} \mathrm{NaCl}, 2.7 \mathrm{mM} \mathrm{KCl}, 4.3 \mathrm{mM}$ Na2HPO4, $1.47 \mathrm{mM} \mathrm{KH} 2 \mathrm{PO} 4)$ and subjected to DNA extraction according to Garcia-Franco, et al. [36]. Isolated DNA from each mosquito was reconstituted in 50 $\mu l$ Tris-EDTA (TE) buffer $(10 \mathrm{mM}$ Tris-Cl, $1 \mathrm{mM}$ EDTA, pH 8.0), and stored at $-20^{\circ} \mathrm{C}$ for PCR $[28,30]$.

\section{Polymerase chain reaction assay}

The PCR reaction was carried out by incubation of 0.20 $\mu \mathrm{M}$ of the corresponding sense and antisense PCR primers, $1 \times$ PCR buffer, $250 \mu \mathrm{M}$ of each dNTP, $2 \mathrm{mM} \mathrm{MgCl}_{2}, 0.15$ $\mathrm{mg} / \mathrm{ml}$ of bovine serum albumin, 2.5 units of Taq polymerase (Applied Biosystems), and approximately 6 ng of genomic DNA per the manufacturer's recommendations.

Amplification of the Ace. 2 gene was performed using primers:

ACEquin (5'-CCTTCTTGAATGGCTGTGGCA-3'), ACEpip (5'-GGAAACAACGACGTATGTACT-3') and

B1246 (5'-TGGAGCCTCCTCTTCACGGC-3') described previously [30]. The PCR conditions were as described previously, briefly: one cycle at $94^{\circ} \mathrm{C}$ for $5 \mathrm{~min}$, followed by 35 cycles of $94^{\circ} \mathrm{C}$ for 30 seconds, $56^{\circ} \mathrm{C}$ for 30 seconds, $72^{\circ} \mathrm{C}$ for 60 seconds, and one final extension of $72^{\circ} \mathrm{C}$ for $5 \mathrm{~min}$.

\section{Results}

\section{Species of collected mosquitoes}

A total of 202,148 mosquito larvae belonging to the genera Culex (77\%), Culiseta (18\%) and Ochlerotatus (5\%) were collected from 3,955 containers from cemeteries in 16 Districts in Mexico City (Additional file 1). Larvae were collected in all sites; $49.5 \%$ of the collected sites yielded $C x$. pipiens complex mosquitoes exclusively; $40.7 \%$ of the sites yielded Ochlerotatus mosquitoes, and $33.9 \%$ of the sites yielded Culiseta mosquitoes. Interestingly, Cx. tarsalis was identified only in Peñon de los Baños (site 87-VC) close to the international airport (Figure 2, 3) coexisting with $C x . p$. quinquefasciatus. Furthermore, $C x$. pipiens complex were coexisting with Culiseta and Ochlerotatus in 25 sites, with Culiseta in 10 sites, and with Ochlerotatus in 17 sites (Figure 2). In this study, we used 3 different land cover classes, urban, suburban and rural areas (Figure $1 \mathrm{~A}-\mathrm{C}$ ) to characterize the landscape in different regions of Mexico City. The 


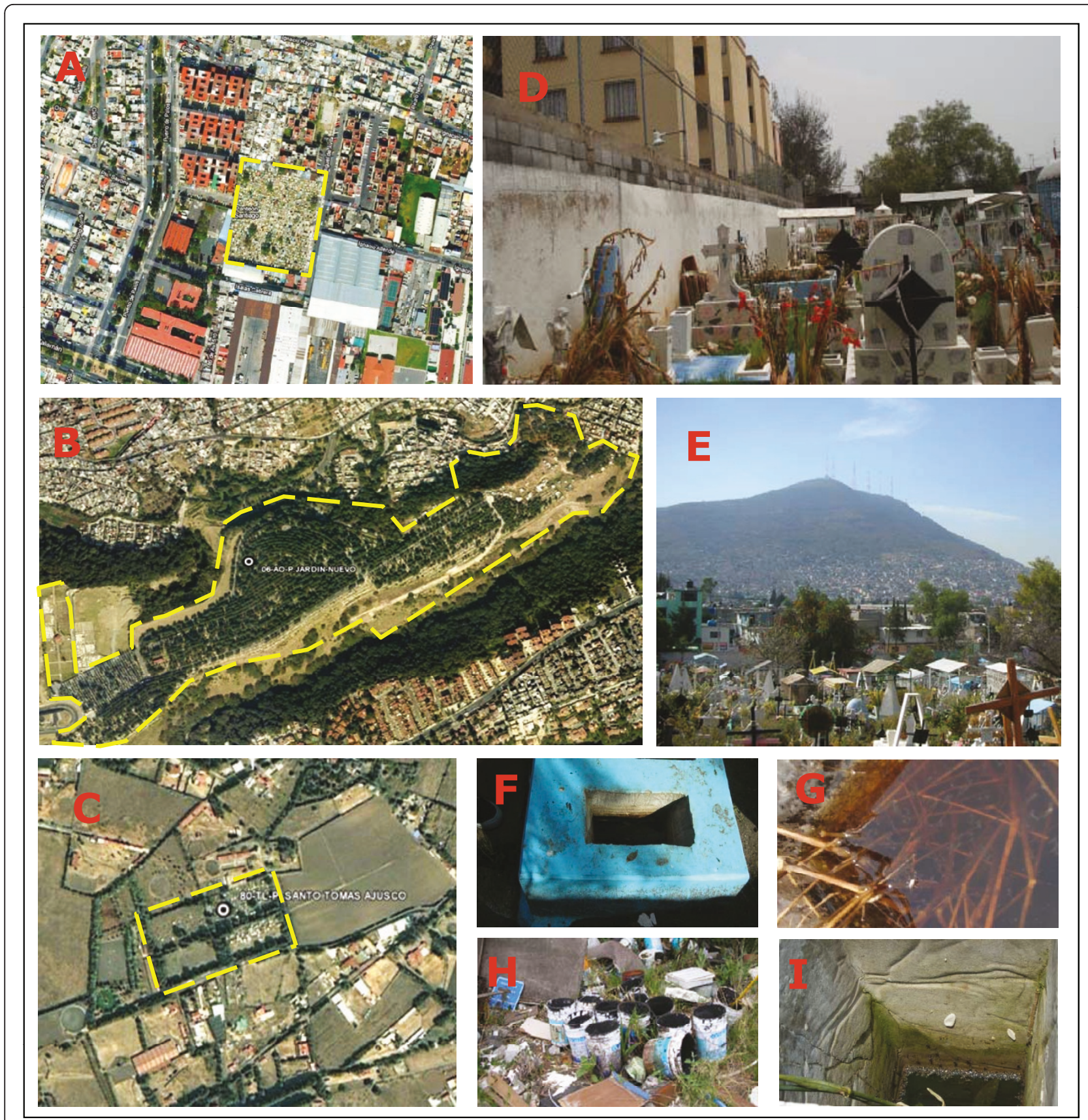

Figure 1 Landscape and habitats of mosquito larval collection sites. (A) Urban area, representative urban area in cemeteries of Mexico City characterized by high human population density, public transportation and communication containing a small amount of green areas. (B) Suburban, this area is constituted for a balance between buildings and green areas with sufficient public transportation and communication but where the people are not dedicated to agricultural activities. (C) Rural, this representative area is characterized by low density human population, with little public transportation and communication and extensive green and agricultural areas. (D-I) Display all varieties of natural and manmade containers representative of the mosquito larval habitats in the collection sites at the cemeteries.

locations of all mosquitoes belonging to the different genera are displayed in Figure 2.

Out of 10,250 Cx. pipiens complex mosquitoes examined, $54.5 \%$ were females and $45.5 \%$ were males (Additional file 1). The male to female ratio was 0.84:1.
Identification of Culex pipiens complex members in Mexico City by DV/D analysis

The locations of the Culex complex mosquito collection sites are shown in Figure 3. The mean value of DV/D ratio of the specimens examined in this study was used 


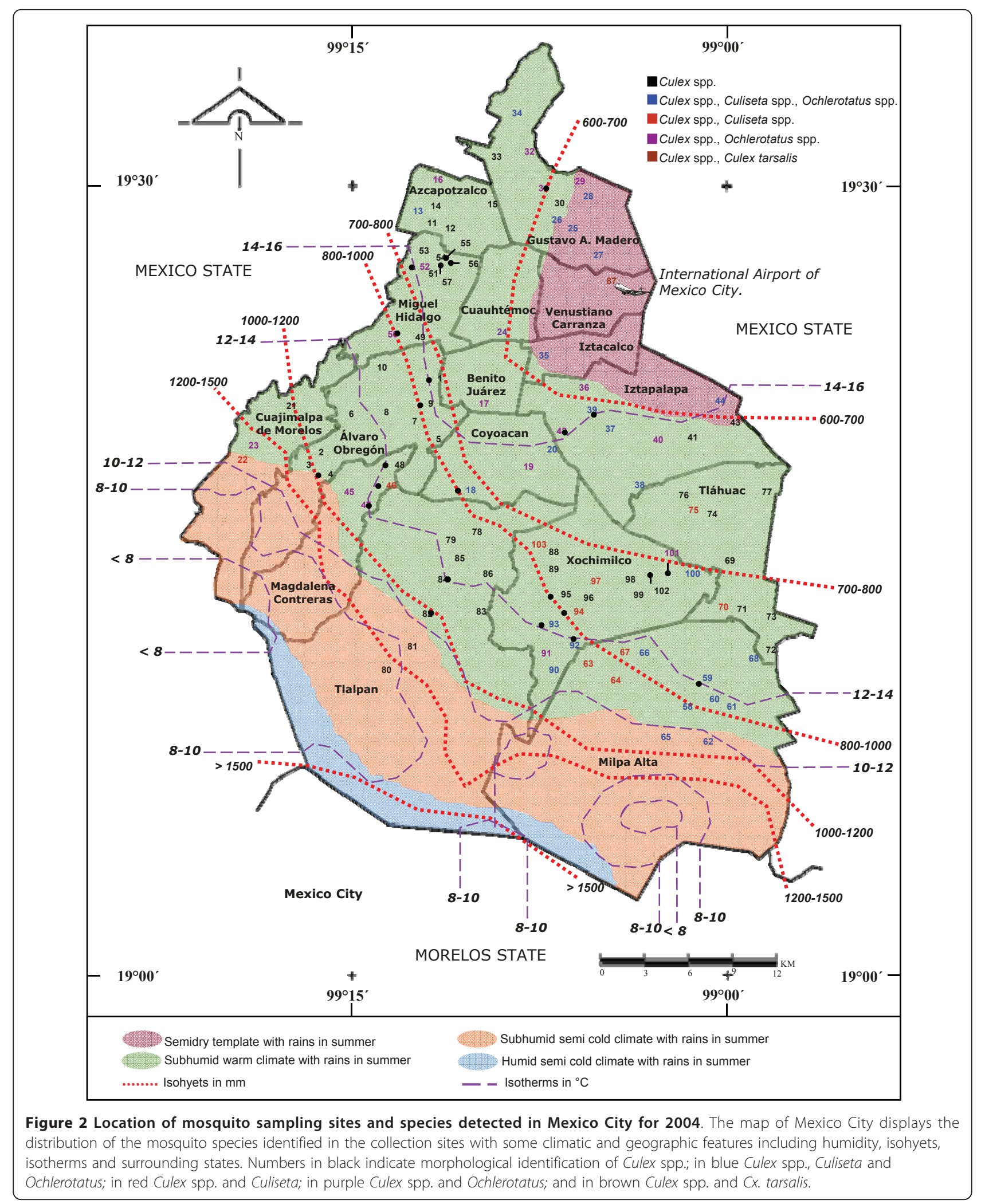

to distinguish $C x$. $p$. pipiens from $C x$. p. quinquefasciatus (Table 1). Cx. p. pipiens had DV/D ratios of less than $0.2, C x . p$. quinquefasciatus had DV/D ratios greater than 0.4 and hybrids displayed intermediate 


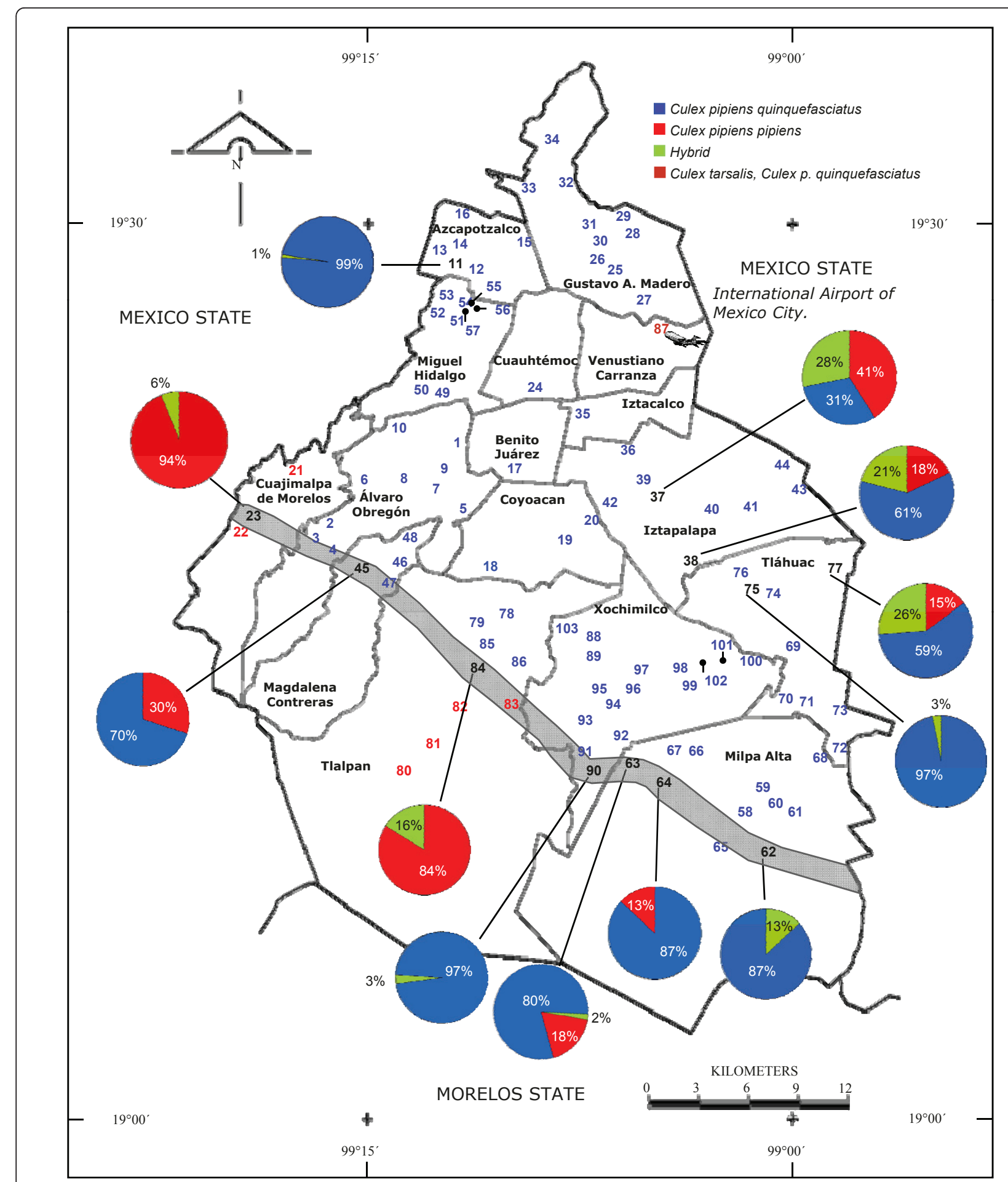

Figure 3 Culex pipiens complex distribution in Mexico City. Map of Cx. p. quinquefasciatus, Cx. p. pipiens and hybrid distribution in all collection sites according to nucleotide differences in the Ace.2 gene. Pie chart graphs (numbers in black) indicate the distributional frequency of identified lineages. The sizes of the pie chart's segments are proportional to the number of mosquitoes identified as $C x$. p. quinquefasciatus (blue), Cx. p. pipiens (red) or hybrid (green). The numbers in blue indicate the sites where CX. p. quinquefasciatus was exclusively identified, red where $C x$. p. pipiens was recognized and in black where hybrids were localized according to chart graphs. In addition the number in brown indicates the site where $C x$. p. quinquefasciatus and $C x$. tarsalis was observed. The grey line approximates the probable hypothetical introgression area. The numbers correspond to the collection sites displayed in the Additional File 1. 
ratios of 0.2-0.4 (Table 1). Most collections consisted of Cx. p. quinquefasciatus (73.8\%) alone and five collections contained only $C x$. p. pipiens $(4.3 \%)$. Two collections consisted of a combination of $C x$. p. pipiens and $C x . p$. quinquefasciatus (1.9\%); Cx. $p$. pipiens, Cx. $p$. quinquefasciatus and hybrids (7.8\%); Cx. p. pipiens and hybrids (1.9\%) or Cx. p. quinquefasciatus and hybrids (9.7\%). Figure 3 shows the locations where $C x . p$. quinquefasciatus (numbers in blue) or $C x$. $p$. pipiens (numbers in red) were identified by morphological analysis and confirmed by molecular analyses (Ace.2 gene).

\section{Molecular Analyses}

In order to distinguish the two nominal taxa, the Ace.2 gene was amplified by polymerase chain reaction (PCR) to detect taxa-specific amplicons. The representative results of the Ace.2 PCR assay for mosquitoes collected from cemeteries in Mexico City are shown in Figure 4. The PCR products of 610 and 274 bp were observed for $C x$. p. pipiens and Cx. p. quinquefasciatus respectively and both fragments were detected for hybrids (Figure 4B). The mosquitoes morphologically identified as $C x$. tarsalis did not yield any PCR product as expected (Figure 4-A, line 10). The DV/D results were generally concordant with the results from the molecular (Ace.2 gene amplification) results. Out of all mosquitoes analyzed there were only 9 mosquitoes identified as hybrids by DV/D analyses that were identified as $C x$. $p$. quinquefasciatus by molecular analysis in (03-AO) Santa Rosa Axochiac (Table 1). In areas where there may be introgression (Figure 3, faint gray line), individuals with $C x . p$. pipiens DV/D ratios were identified as hybrids by molecular analysis and a few with $C x . p$. quinquefasciatus DV/D ratios were also identified as hybrids. Interestingly, the most "observable" band correlated best with the morphological analysis. Our molecular analysis revealed that the frequency of members of the $C x$. pipiens complex in the collection sites was: $C x . p$. quinquefasciatus $=95.5 \%$, $C x$. $p$. pipiens $=14 \%$ and hybrids $=10 \%$.

$C x$. p. pipiens or Cx. p. quinquefasciatus were identified during the whole year in El Calvario (21-CJ), Cuajimalpa de Morelos and in Sanctorum (52-MH), Miguel Hidalgo respectively (Additional file 2). Furthermore hybrids identified in the samples from San Nicolas Tolentino in Ixtapalapa (37-IP) and from La Concordia in Cuajimalpa (23-CJ) are displayed in the Additional file 2 .

\section{Seasonal Rainfall Contribution}

In order to determine the influence of seasonal rainfall on the abundance of $C x$. pipiens complex-mosquitoes, we analyzed molecularly 600 mosquitoes/month collected in six cemeteries during the rainy season from May to October in 2005 (Table 2). Culex pipiens- quinquefasciatus hybrid mosquitoes were found in all six collection sites. Mosquitoes were collected once per month from 10 different containers at each site. Hybrids were detected in the Azcapotzalco site from Jun to October, in the Milpa Alta site in July, in the Cuajimalpa site from July to October, in the Tlahuac site from June to October, in the Ixtapalapa site in June and from August to October, and finally in the Xochimilco site in June and July (Table 2). Furthermore, hybrid mosquito densities were qualitatively higher during the rainy season. Hybrids were not observed throughout the year. Notably they were not detected in the dry months (January to May). Two peaks in abundance of hybrid mosquitoes were observed (Additional file 2): the first in June and the second in August at the cemetery Civil San Nicolas Tolentino (37-IP site). Temperatures at the collection sites fluctuated from $8^{\circ} \mathrm{C}$ to $23^{\circ} \mathrm{C}$. Hybrids were found at temperatures from $12.5^{\circ} \mathrm{C}$ to $17^{\circ} \mathrm{C}$.

\section{Discussion}

The mosquitoes belonging to the genera Culex, Culiseta and Ochlerotatus collected and identified in Mexico City are capable of transmitting pathogens causing many different diseases, including WNV. Mosquitoes belonging to the $C x$. pipiens complex, their hybrids, and $C x$. tarsalis are considered important vectors for WNV, which can cause fever, death, and long term sequelae in infected humans and also death in horses [37]. WNV is primarily enzootic among birds [38], with humans and equines serving as incidental or dead-end hosts [39]. Migratory birds can spread the virus over long distances $[40,41]$. WNV is responsible for human outbreaks in the United States, Europe, and the Middle East $[6,15,42]$. Mexico City has similar climatic conditions to other cities where outbreaks of WNV have occurred. West Nile virus has been reported in six Mexican states $[43,44]$, which increases the probability of introduction of the virus into Mexico City. Little is known about the distribution of $C x$. pipiens complex mosquitoes in the city. This information is essential for assessing the epidemic potential of WNV in Mexico City. West Nile Virus has been detected in Culex spp. mosquitoes in the United States since 1999, and has spread across most states [42], resulting in 30,658 human cases with 1,206 deaths by the end of 2010. The virus reached Canada in 2001 and countries of the Caribbean and Central America by $2003[44,45]$. WNV was detected in horses in the Mexican states of Veracruz, Yucatan, Chihuahua, Coahuila, Tamaulipas, Tabasco in 2002 [24]. However, the virus was not detected in horse samples from Durango, San Luis Potosí, Jalisco, Distrito Federal, Guerrero, Puebla, Oaxaca and Chiapas were negative for WNV [24]. The first two autochthonous human cases of confirmed WNV infection in Mexico were reported in Nuevo Leon 
Table 1 Climatic conditions and percentage of hybrids collected from the different cemeteries

\begin{tabular}{|c|c|c|c|c|c|c|c|c|c|c|c|c|}
\hline \multirow[t]{2}{*}{ Key } & \multirow[t]{2}{*}{ Rain(mm/year) } & \multirow[t]{2}{*}{ 'T $\left({ }^{\circ} \mathrm{C}\right)$} & \multirow{2}{*}{$\begin{array}{l}{ }^{\dagger} \text { W. T. }\left(^{\circ}\right. \\
\text { C) }\end{array}$} & \multirow{2}{*}{$\begin{array}{l}{ }^{8} \text { R. } \\
\text { H. (\%) }\end{array}$} & \multirow[t]{2}{*}{$\mathrm{pH}$} & \multirow[t]{2}{*}{ Total larvae } & \multicolumn{3}{|c|}{ Morphological Identification (\%) } & \multicolumn{3}{|c|}{ Molecular Identification (\%) } \\
\hline & & & & & & & $\begin{array}{l}\text { Cx.p. } \\
\text { quinque- } \\
\text { fasciatus }\end{array}$ & $\begin{array}{l}\text { Cx.p. } \\
\text { pipiens }\end{array}$ & Hybrid & $\begin{array}{l}\text { Cx. p. } \\
\text { quinque- } \\
\text { fasciatus }\end{array}$ & $\begin{array}{l}\text { Cx.p. } \\
\text { pipiens }\end{array}$ & Hybrid \\
\hline
\end{tabular}

\begin{tabular}{|c|c|c|c|c|c|c|c|c|c|c|c|c|}
\hline $\mathrm{AO}$ & 29.1 & 15.1 & 14.2 & 33.8 & 7.2 & & & & & & & \\
\hline $03-\mathrm{AO}^{* *}$ & 38 & 15.4 & 13.9 & 36 & 7.9 & 2030 & 91 & 0 & 9 & 100 & 0 & 0 \\
\hline$\overline{A Z}$ & 69.8 & 17.5 & 15.5 & 39.3 & 6.9 & & & & & & & \\
\hline$\overline{11-A Z^{*}}$ & 61 & 17 & 15 & 42 & 7 & 2200 & 98 & 0 & 2 & 99 & 0 & 1 \\
\hline$\overline{C J}$ & 225 & 13.3 & 11 & 43 & 7.1 & & & & & & & \\
\hline $21-\left(J^{* *}\right.$ & 225 & 14 & 13 & 56 & 7.2 & 2790 & 0 & 81 & 19 & 0 & 100 & 0 \\
\hline $22-C J^{* * *}$ & 225 & 11 & 8 & 37 & 7 & 1360 & 0 & 100 & & 0 & 100 & 0 \\
\hline $23-C J^{* *}$ & 225 & 15 & 12 & 36 & 7.1 & 865 & 0 & 72 & 28 & 0 & 94 & 6 \\
\hline$\overline{\mathrm{GM}}$ & 105.7 & 18 & 17.2 & 47.8 & 7.3 & & & & & & & \\
\hline $26-\mathrm{GM}^{*}$ & 107 & 17 & 15 & 56 & 7.2 & 710 & 98 & 0 & 2 & 100 & 0 & 0 \\
\hline IP & 90.1 & 17.1 & 15.6 & 40.1 & 7.2 & & & & & & & \\
\hline $37-I P^{*}$ & 85 & 16 & 14 & 57 & 7.2 & 4765 & 22 & 39 & 39 & 31 & 41 & 28 \\
\hline $38-\mid P^{* * *}$ & 85 & 17 & 15 & 52 & 7.5 & 2345 & 53 & 22 & 25 & 61 & 18 & 21 \\
\hline 39-IP* & 85 & 15.5 & 14 & 34 & 7.2 & 1710 & 99 & 1 & 0 & 100 & 0 & 0 \\
\hline$\overline{44-I P^{*}}$ & 94 & 16 & 16 & 36 & 7 & 2640 & 97 & 0 & 3 & 100 & 0 & 0 \\
\hline$\overline{M C}$ & 204 & 12.5 & 11.5 & 57.5 & 7.18 & & & & & & & \\
\hline $45-\mathrm{MC}^{*}$ & 204 & 12 & 11 & 62 & 7.3 & 845 & 67 & 29 & 4 & 70 & 30 & 0 \\
\hline $47-\mathrm{MC}^{*}$ & 204 & 12 & 10 & 58 & 7.1 & 995 & 67 & 0 & 33 & 100 & 0 & 0 \\
\hline$\overline{M A}$ & 140 & 14.2 & 13.4 & 34.7 & 7.4 & & & & & & & \\
\hline $62-M A^{* *}$ & 140 & 13.8 & 12.5 & 34 & 7.3 & 2895 & 73 & 0 & 27 & 87 & 0 & 13 \\
\hline $63-M A^{* * *}$ & 140 & 13.2 & 11.8 & 36 & 7.7 & 1845 & 68 & 9 & 23 & 80 & 18 & 2 \\
\hline $64-M A^{* * *}$ & 140 & 13.6 & 12.2 & 35 & 7.8 & 2420 & 87 & 13 & 0 & 87 & 13 & 0 \\
\hline $65-M A^{* *}$ & 140 & 13.9 & 13 & 33 & 6.9 & 619 & 94 & 0 & 6 & 100 & 0 & 0 \\
\hline TH & 111.2 & 16.2 & 15.9 & 59.1 & 7 & & & & & & & \\
\hline 73-TH* & 107 & 16 & 16 & 82 & 7.2 & 2680 & 71 & 0 & 29 & 100 & 0 & 0 \\
\hline $75-\mathrm{TH}^{* *}$ & 156 & 16 & 15.5 & 62 & 6.9 & 1140 & 56 & 3 & 41 & 97 & 0 & 3 \\
\hline 77-TH*** & 96 & 17 & 16.5 & 52 & 6.6 & 1290 & 61 & 18 & 21 & 59 & 15 & 26 \\
\hline$\overline{\mathrm{TL}}$ & 184.1 & 12.3 & 9.8 & 44.9 & 7.2 & & & & & & & \\
\hline 78-TL* & 145 & 13.5 & 11 & 35 & 7 & 3720 & 82 & 0 & 18 & 100 & 0 & 0 \\
\hline $80-\mathrm{TL}^{* * *}$ & 219 & 8 & 6 & 55 & 7.8 & 1450 & 0 & 100 & 0 & 0 & 100 & 0 \\
\hline $81-\mathrm{TL}^{* * *}$ & 219 & 11.5 & 7 & 52 & 7.3 & 1795 & 0 & 100 & 0 & 0 & 100 & 0 \\
\hline $82-\mathrm{TL}^{* *}$ & 219 & 12.5 & 7 & 54 & 7.1 & 2130 & 0 & 100 & 0 & 0 & 100 & 0 \\
\hline $83-\mathrm{TL}^{* *}$ & 219 & 11 & 8 & 52 & 7.2 & 1690 & 0 & 100 & 0 & 0 & 100 & 0 \\
\hline $84-\mathrm{TL}^{* *}$ & 145 & 13 & 11.5 & 42 & 7.2 & 940 & 12 & 37 & 51 & 0 & 84 & 16 \\
\hline XOo & 78.8 & 15.7 & 13.9 & 36.3 & 7.1 & & & & & & & \\
\hline $90-X O^{* * *}$ & 177 & 9 & 5 & 27 & 7.1 & 930 & 88 & 2 & 10 & 97 & 0 & 3 \\
\hline $91-X O^{* *}$ & 116 & 8 & 8 & 28 & 7 & 2590 & 76 & 0 & 24 & 100 & 0 & 0 \\
\hline
\end{tabular}

Temperature, ${ }^{\dagger}$ Water temperature, ${ }^{\circledR}$ Relative humidity, *Urban, ${ }^{* *}$ Suburban, ${ }^{* * *}$ Rural.

and Sonora in 2005 [45]. To our knowledge, only 8 human cases of WNV infection have occurred in Mexico, 3 of which were severe but did not result in death [41]. One fatal human case was reported in Nuevo Leon, Mexico in 2005 [44] and 6 more cases in the northern Mexico in a survey from 2005 to 2007 [46]. In addition there are other reports that suggest that because there are many cases of dengue (DENV) in Mexico it also may be that the human Mexican hosts had antibodies against DENV that can block WNV 
A

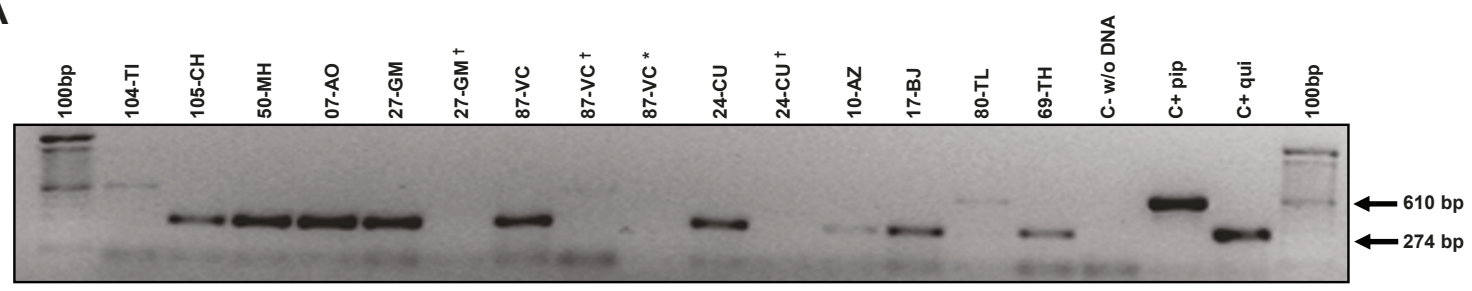

B

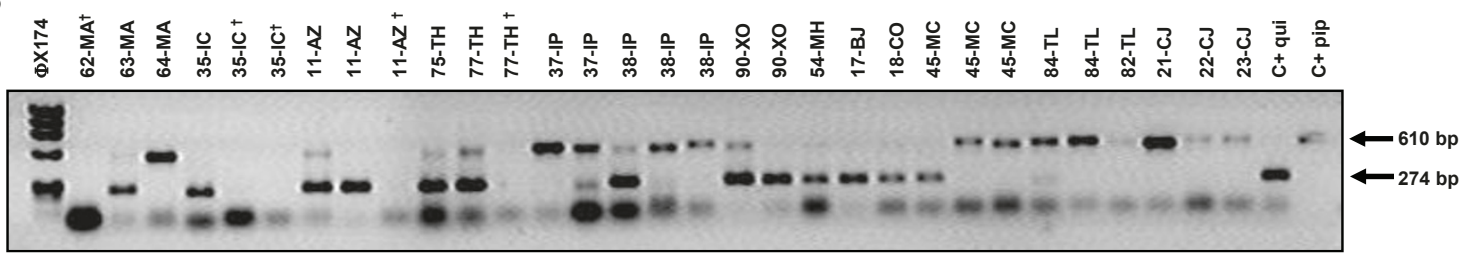

Figure 4 PCR amplification of the Ace.2 gene. Larvae collected at various cemeteries in Mexico City were reared to mosquito adults and then identified by PCR amplification of the Ace.2 gene [30]. The CX. p. pipiens specific band of $610 \mathrm{bp}$ and Cx. p. quinquefasciatus specific band of 274 bp and the expected bands of 610 and 274 bp for hybrids (panel B) are displayed in the agarose gels. ${ }^{*} C x$. tarsalis identified by morphological analysis did not produce a PCR amplicon. ${ }^{\dagger}$ Culex spp. mosquitoes that were not identified as pertaining to the $C x$. pipiens complex or hybrids by morphological analysis or by the Ace.2 gene assay.

activity [46]. However, since there has been no DENV activity in Mexico City, people from Mexico City could more likely be infected by the virus, if antibodies against DENV have any role in blocking WNV infection. The introduction and establishment of WNV in Mexico City-which would be a public health disaster-is a possibility because the Culex vectors are present throughout the city.

Virus introduction could occur in a variety of ways including migration of WNV infected birds or humans or by infected mosquitoes on airplanes. WNV outbreaks that occur sporadically in southern Europe are attributed to importation of the virus by migratory birds from Africa, which then infect local mosquitoes [47]. Culex

Table 2 Members of the Culex pipiens complex and hybrids identified by Ace

\begin{tabular}{lllllll}
\hline Cemetery & MAY & JUN & JUL & AUG & SEP & OCT \\
\hline Santa Lucia, Azcapozalco & q & $\mathbf{h}$ & $\mathbf{h}$ & $\mathbf{h}$ & $\mathbf{h}$ & $\mathbf{h}$ \\
\hline La Concordia, Cuajimalpa & q & p & $\mathbf{h}$ & $\mathbf{h}$ & $\mathbf{h}$ & $\mathbf{h}$ \\
\hline San Nicolas Tolentino, Iztapalapa & q & $\mathbf{h}$ & $\mathrm{p}$ & $\mathbf{h}$ & $\mathbf{h}$ & $\mathbf{h}$ \\
\hline $\begin{array}{l}\text { San Salvador Cuauhtenco, Milpa } \\
\text { Alta }\end{array}$ & ND & q & $\mathbf{h}$ & $\mathrm{p}$ & $\mathrm{p}$ & $\mathrm{p}$ \\
\hline Santa Catarina, Tlahuac & $\mathrm{q}$ & $\mathbf{h}$ & $\mathbf{h}$ & $\mathbf{h}$ & $\mathbf{h}$ & $\mathbf{h}$ \\
\hline $\begin{array}{l}\text { San Francisco Tlalnepantla, } \\
\text { Xochimilco }\end{array}$ & $\mathrm{p}$ & $\mathbf{h}$ & $\mathbf{h}$ & $\mathrm{q}$ & $\mathrm{q}$ & $\mathrm{p}$ \\
\hline
\end{tabular}

Samples were taken from six cemeteries and tested for Ace.2 gen to determine $C x$. p. quinquefasciatus (q), Cx. p. pipiens (p) or their hybrids (h). spp. mosquitoes are frequently collected from airplanes [48], and it is possible that WNV could have been introduced into New York City in 1999 by an infected mosquito transported from the Middle East. In this regard Mexico City is served by Mexico City International Airport, Latin America's busiest and largest airport, with regular (daily) flights to North America, mainland Mexico, Central America and the Caribbean, South America, Europe and Asia, has code share agreements spanning the entire globe. It is now used by over 26 million passengers per year [49], and in 2008, about 31 million people went through the city's airports. With high traffic volume to and from endemic areas Mexico City is at risk for introduction of WNV. Interestingly, $C x$. tarsalis was only detected in one site close to the international airport suggesting possible transport of this mosquito via aircraft as has occurred in other countries [48]. This suggestion is based on the fact that we did not find this mosquito in any other collection sites, even though collections were made in natural ground pools and water present for less than a week that is preferred by $C x$. tarsalis [48]. Our results display for the first time the prevalence and distribution of the Cx. pipiens complex in the city, which will help to vector control efforts in the event of introduction of the virus. We note that in this study only larval habitats from cemeteries were sampled to make the most efficient use of available resources. A broader sample of land use classes (e.g., industrial, highdensity housing, commercial, etc.) may have produced 
slightly different results. Similarly, the use of light traps would likely produce different relative abundances given the known differences in response to light traps. In the case of larval sampling versus light traps, larval sampling-if it is sufficiently thorough-is more likely to sample the entire complex of species. Cemeteries, because of their accessibility, are an effective proxy for the larger surrounding area. Surveys of other land use classes are planned in future projects.

It is very clear that $C x . p$. pipiens and $C x . p$. quinquefasciatus are closely associated with humans. Hybrid zones between the two species are known to occur in North America, Argentina, and Madagascar [25,50,51]. Mexico City has approximately 103 cemeteries surrounded by houses and apartments (Figure 1). The crypt vases contain water throughout the year, providing mosquito breeding sites [52]. Cemeteries sampled during this study confirmed the presence of $C x$. pipiens complex and $C x$. tarsalis mosquitoes in Mexico City. Our results show for the first time that $C x . p$. pipiens, $C x . p$. quinquefasciatus, their hybrids and $C x$. tarsalis are all present in Mexico City. Previously, $C x$. p. pipiens was thought to be found only in the United States and Canada [26]. Furthermore, Mexico City was not included in those previous reports.

Based upon DV/D values and ribosomal DNA analysis [30], specimens from extreme isotherms $12-14{ }^{\circ} \mathrm{C}$ to the North of Mexico City were unambiguously identified as Cx. p. quinquefasciatus. This is the first report for Mexico City and it is in agreement with previous studies showing that only $C x . p$. quinquefasciatus is usually found south of $36^{\circ} \mathrm{N}$ in North America [26]. Culex pipiens pipiens mosquitoes were detected above isotherms $12-14{ }^{\circ} \mathrm{C}$ to the South of Mexico City. Finally, $C x$. p. pipiens-quinquefasciatus hybrids were detected between isotherms $10-12{ }^{\circ} \mathrm{C}$ and isotherms $12-14^{\circ} \mathrm{C}$ at Cuajimalpa, Alvaro Obregon, Magdalena Contreras, Tlalpan, Xochimilco and Milpa Alta Districts (Figure 2). Culex pipiens pipiens mosquitoes were also collected during the whole year in the cemetery "El Calvario" in Cuajimalpa de Morelos, suggesting mosquito adaptation to this region.

Hybrids were collected in the rainy season from June to October from northwest to southeast of the city, where there was high mosquito density. The abundance of hybrid mosquitoes increased in the late summer (Cuajimalpa, Iztalapa, Azcapozalco, Xochimilco, Milpa Alta and Tlahuac) between September and October associated with a decrease in temperature (Table 2).

We are suggesting a hypothetical hybridization region (Figure 3) revealing the distribution limits of $C x$. $p$. quinquefasciatus and $C x$. p. pipiens without any apparent geographic barrier. This is based on the apparent spatial limits of $C x . p$. quinquefasciatus and $C x . p$. pipiens populations, with the localization of hybrid mosquitoes occurring between them. Additional studies are needed to demonstrate that this is a true introgression area. Culex pipiens pipiens were detected principally in suburban or rural lands and $C x . p$. quinquefasciatus were detected primarily in urban zones, which has been reported previously [53]. Interestingly, in the Northeast districts of Iztapalapa and Tlahuac, there was no apparent division between the $C x$. pipiens complex mosquitoes; with $C x . p$. quinquefasciatus, $C x . p$. pipiens and hybrids found in the same collection sites (Figure 3).

It has been suggested that hybridization between $C x$. p. pipiens and $C x . p$. quinquefasciatus mosquitoes may have facilitated the rapid spread of West Nile virus in North America [16]. Our studies support the presence of a self-sustaining hybrid population in Mexico City (Figure 2). This is similar to results of previous studies in Colorado [28], California [25,54], and Tennessee [55]. The nature of the hybrid populations in Mexico City requires further study. Microsatellite markers have been used to assess introgression between $C x$. p. pipiens and Cx. p. quinquefasciatus [56], and this population genetic approach could be used to further define the extent and geographic regions of introgression. It should also be noted that the presence of $C x$. $p$. pipiens itself could pose a risk to humans in Mexico City, as there are reports that this species may shift feeding preferences from birds to humans in urban areas during late summer and early fall [57].

Our analyses provide insight into the distribution of $C x$. pipiens complex mosquitoes in Mexico City. This is important as behavioral differences, such as host-feeding preferences, are important in determining the vectorial capacity of mosquitoes from this complex. This information is necessary for establishing effective surveillance and targeted control programs to prevent or control WNV outbreaks.

\section{Conclusions}

Culex pipiens pipiens, $C x$. p. quinquefasciatus and $C x$. tarsalis are important vectors for WNV, that occur in Mexico City. Hybrids of $C x . p$. pipiens and $C x$. p. quinquefasciatus were detected by DV/D ratio and molecular analysis. Hybrids were identified during the rainy season from June to October, in an introgression region extending from the northwest to southeast of the city. Clearly, Mexico City has an abundance of competent Culex spp. vectors and is at risk for introduction of WNV and epidemic disease. Increased surveillance and effective vector control should be implemented in order to avoid the risk of an epidemic of WNV in this highly populated city. 


\section{Additional material}

\section{Additional File 1: Geographic location of cemeteries and} percentage of male mosquitoes obtained.

Additional File 2: PCR amplification of the Ace.2 gene from two different cemeteries in 2005. (A) Samples from cemetery "El Calvario" in Cuajimalpa de Morelos borough. All PCR products correspond with the Cx. p. pipiens (610 bp) in each month during 2005. B) Samples from cemetery "Sanctorum" in Miguel Hidalgo borough where the PCR products correspond with CX. p. quinquefasciatus (274 bp) in each month during 2005. C) Samples from "San Nicolas Tolentino" in Ixtapalapa (37-IP) and from "La Concordia" in Cuajimalp (23-CJ) boroughs where the PCR products correspond with hibryds (610 and $274 \mathrm{bp}$. Negative controls are indicated as C-Cs.DNA (Culiseta). Positive controls are indicated as C+pip, $\mathrm{C}+$ qui and 52-MH2004(C+). 100 bp DNA Ladders are in lines 1 panel A, line 17 panel $B$ and line 1 panel $C$ on the right side; and $\phi \times 174$ DNA Hae III ladder on panel C left side. Arrows show the bands of $274 \mathrm{bp}$ and $610 \mathrm{bp}$ in all panels.

\section{Acknowledgements}

We wish to thank the Biotechnological Engineer Juan Jose Alcala Huerta and the Technician in Biotechnology Karla Balderrama Martínez for their assistance in mosquito rearing during the course of these experiments.

\section{Author details}

'Department of Genetics and Molecular Biology, Centro de Investigación y de Estudios Avanzados del Instituto Politécnico Nacional, Ave. Instituto Politécnico Nacional No. 2508, San Pedro Zacatenco-Gustavo A. Madero, México D.F., C.P. 07360, México. ${ }^{2}$ Department of Microbiology, Immunology \& Pathology, Colorado State University (CSU), Fort Collins, Colorado, USA. ${ }^{3}$ Public Health Laboratory of State of Oaxaca, Km. 18.5 Carr. Oaxaca-Sola de Vega, Reyes Mantecon-Oaxaca de Juárez, C.P. 68000, Oaxaca México. ${ }^{4}$ University of Tecamac, Tecamac-Estado de México, México. ${ }^{5}$ Genomics Science Program, Autonomous University of México City, Ave. San Lorenzo No. 290, Del Valle-Benito Juárez, C.P. 03100, México. ${ }^{6}$ Campamento de Obras Viales, Departamento del Distrito Federal, México D.F., México.

\section{Authors' contributions}

ADB made all mosquito collections, carried out the morphological and molecular analysis of mosquitoes and participated in the writing and discussion of results; BGB and CGM supported molecular analysis confirmation, read and approved the final manuscript; GPR helped to rear the mosquitoes, participated in the writing and discussion of results and assisted with the literature validation; JPMM helped to confirm the morphological mosquito analysis of all collections; AAPV participated in the molecular analysis of the mosquitoes collected; MCN participated in discussion of results; ADP helped to make all mosquito collections; BJB and CGM participated in discussion of results, review of the manuscript, assisted with the literature selection and validation, and proof-read the manuscript; MLM participated in writing, analysis and discussion of results, review the manuscript, assisted with the literature validation and proof-read and assembled the manuscript. All authors participated in the discussion of results and read and approved the final manuscript.

\section{Competing interests}

The authors declare that they have no competing interests.

Received: 23 February 2011 Accepted: 9 May 2011

Published: 9 May 2011

\section{References}

1. Viral hemorrhagic fevers. [http://www.cdc.gov/ncidod/dvrd/spb/mnpages/ dispages/vhf.htm].

2. Arboviral encephalitides. [http://www.cdc.gov/ncidod/dvbid/Arbor/index. htm].

3. Van den Hurk AF, Ritchie SA, Mackenzie JS: Ecology and geographical expansion of Japanese encephalitis virus. Annual Review of Entomology 2009, 54:17-35.
4. West Nile virus. [http://www.cdc.gov/ncidod/dvbid/westnile/index.htm].

5. Blitvich B: Transmission dynamics and changing epidemiology of West Nile virus. Anim Hith Res Rev 2008, 9:71-86.

6. Hayes EB, Komar N, Nasci RS, Montgomery SP, O'Leary DR, Campbell GL: Epidemiology and transmission dynamics of West Nile virus disease. Emerg Infect Dis 2005, 11:1167-1173.

7. Nayar JK, Knight JW, Munstermann LE: Temporal and geographic genetic variation in Culex pipiens quinquefasciatus (Diptera: Culicidae) from Florida. J Med Entomol 2003, 40:882-889.

8. Urbanelli S, Bullini L, Villani F: Electrophoretic studies on Culex quinquefasciatus Say from Africa: genetic variability and divergence from Culex pipiens L.(Diptera: Culicidae). Bull Entomol Res 1985, 75:291-304.

9. Vinogradova EB: Culex pipiens pipiens mosquitoes: Taxonomy, distribution, ecology, physiology, genetics, applied importance and control Moscow: Pensoft Pub; 2000.

10. Anderson JF, Andreadis TG, Vossbrinck CR, Tirrell S, Wakem EM, French RA, Garmendia $A E$, Van Kruiningen HJ: Isolation of West Nile virus from mosquitoes, crows, and a Cooper's hawk in Connecticut. Science 1999, 286:2331-2333.

11. Bell JA, Mickelson NJ, Vaughan JA: West Nile virus in host-seeking mosquitoes within a residential neighborhood in Grand Forks, North Dakota. Vector-Borne Zoonotic Dis 2005, 5:373-382.

12. DiMenna MA, Bueno R Jr, Parmenter RR, Norris DE, Sheyka JM, Molina JL, LaBeau EM, Hatton ES, Glass GE: Emergence of West Nile virus in mosquito (Diptera: Culicidae) communities of the New Mexico Rio Grande Valley. J Med Entomol 2006, 43:594-599.

13. Goddard LB, Roth AE, Reisen WK, Scott TW: Vector competence of California mosquitoes for West Nile virus. Emerg Infect Dis 2002, 8:1385-1391.

14. Reisen W, Lothrop H, Chiles R, Madon M, Cossen C, Woods L, Husted S, Kramer V, Edman J: West Nile virus in California. Emerg Infect Dis 2004, 10:1369-1378.

15. Bernard KA, Maffei JG, Jones SA, Kauffman EB, Ebel G, Dupuis AP, Ngo KA, Nicholas DC, Young DM, Shi PY, et al: West Nile virus infection in birds and mosquitoes, New York State, 2000. Emerg Infect Dis 2001, 7:679-685.

16. Fonseca DM, Keyghobadi N, Malcolm CA, Mehmet C, Schaffner F, Mogi M, Fleischer RC, Wilkerson RC: Emerging vectors in the Culex pipiens complex. Science 2004, 303:1535-1538.

17. Andreadis TG, Armstrong PM, Bajwa Wl: Studies on hibernating populations of Culex pipiens from a West Nile virus endemic focus in New York City: Parity rates and isolation of West Nile virus. J Am Mosq Control Assoc 2010, 26:257-264.

18. Higgs S, Snow K, Gould EA: The potential for West Nile virus to establish outside of its natural range: $A$ consideration of potential mosquito vectors in the United Kingdom. Trans R Soc Trop Med Hyg 2004, 98:82-87.

19. Pesko K, Mores CN: Effect of sequential exposure on infection and dissemination rates for West Nile and St. Louis encephalitis viruses in Culex quinquefasciatus. Vector-Borne Zoonotic Dis 2009, 9:281-286.

20. Turell MJ, Presley SM, Gad AM, Cope SE, Dohm DJ, Morrill JC, Arthur RR: Vector competence of Egyptian mosquitoes for Rift Valley fever virus. Am J Trop Med Hyg 1996, 54:136-139.

21. Weng MH, Lien JC, Lin CC, Yao CW: Vector competence of Culex pipiens molestus (Diptera: Culicidae) from Taiwan for a sympatric strain of Japanese encephalitis virus. J Med Entomol 2000, 37:780-783.

22. Evans BR, Joyce CR, Porter JE: Mosquitoes and other arthropods found in baggage compartments of international aircraft. Mosq News 1963, 23:9-12.

23. Goh KT, Ng SK, Kumarapathy S: Disease-bearing insects brought in by international aircraft into Singapore. Southeast Asian J Trop Med Public Health 1985, 16:49-53.

24. Estrada-Franco JG, Navarro-Lopez R, Beasley DW, Coffey L, Carrara AS, Travassos da Rosa A, Clements T, Wang E, Ludwig GV, Cortes AC, et al: West Nile virus in Mexico: Evidence of widespread circulation since July 2002. Emerg Infect Dis 2003, 9:1604-1607.

25. Cornel AJ, McAbee RD, Rasgon J, Stanich MA, Scott TW, Coetzee M: Differences in extent of genetic introgression between sympatric Culex pipiens and Culex quinquefasciatus (Diptera: Culicidae) in California and South Africa. J Med Entomol 2003, 40:36-51.

26. Barr AR: The distribution of Culex $p$. pipiens and Culex p. quinquefasciatus in North America. Am J Trop Med Hyg 1957, 6:153-165. 
27. Sanogo YO, Kim CH, Lampman R, Halvorsen JG, Gad AM, Novak RJ: Identification of male specimens of the Culex pipiens complex (Diptera: Culicidae) in the hybrid zone using morphology and molecular techniques. J Med Entomol 2008, 45:203-209.

28. Aspen S, Savage HM: Polymerase chain reaction assay identifies North American members of the Culex pipiens complex based on nucleotide sequence differences in the acetylcholinesterase gene Ace.2. J Am Mosq Control Assoc 2003, 19:323-328.

29. Bahnk CM, Fonseca DM: Rapid assay to identify the two genetic forms of Culex (Culex) pipiens L. (Diptera: Culicidae) and hybrid populations. Am J Trop Med Hyg 2006, 75:251-255.

30. Smith $\lrcorner$, Fonseca DM: Rapid assays for identification of members of the Culex (Culex) pipiens complex, their hybrids, and other sibling species (Diptera: Culicidae). Am J Trop Med Hyg 2004, 70:339-345.

31. Kottek M, Grieser J, Beck C, Rudolf B, Rubel F: World Map of the KoppenGeiger climate classification updated. Meteorol Z 2006, 15:259-264.

32. Estadísticas de población en México. [http://72.52.156.225/Estudio.aspx? Estudio=estadisticas-poblacion-mexico].

33. Situación demográfica de la Ciudad de Mexico. [http://www.conapo.gob. $\mathrm{mx} /$ index.php?option $=\mathrm{com}$ content\&view $=$ article\&id $=301 \&$ ltemid $=418]$.

34. McAbee RD, Green EN, Holeman J, Christiansen J, Frye N, Dealey K, Mulligan FS, Brault AC, Cornel AJ: Identification of Culex pipiens complex mosquitoes in a hybrid zone of West Nile virus transmission in Fresno County, California. Am J Trop Med Hyg 2008, 78:303-310.

35. Sundararaman S: Biometrical studies on intergradation in the genitalia of certain populations of Culex pipiens and Culex quinquefasciatus in the United States. Am J Epidemiol 1949, 50:307-314.

36. Garcia-Franco F, Munoz Mde L, Lozano-Fuentes S, Fernandez-Salas I, GarciaRejon J, Beaty B, Black WC: Large genetic distances among Aedes aegypti populations along the South Pacific coast of Mexico. Am J Trop Med Hyg 2002, 66:594-598.

37. Kulasekera VL, Kramer L, Nasci RS, Mostashari F, Cherry B, Trock SC, Glaser C, Miller JR: West Nile virus infection in mosquitoes, birds, horses, and humans, Staten Island, New York, 2000. Emerg Infect Dis 2001, 7:722-725.

38. Malkinson $M$, Banet $C$ : The role of birds in the ecology of West Nile virus in Europe and Africa. Curr Top Microbiol Immunol 2002, 267:309-322.

39. Murgue B, Murri S, Zientara S, Durand B, Durand JP, Zeller H: West Nile outbreak in horses in southern France, 2000: the return after 35 years. Emerg Infect Dis 2001, 7:692-696.

40. Hannoun C, Corniou B, Mouchet J: Role of migrating birds in arbovirus transfer between Africa and Europe. In Transcontinental connections of migratory birds and their role in the distribution of arboviruses. Edited by: Cherepanov Al. Novosibirsk, Russia: Nauka; 1972:167-172.

41. Rappole JH, Derrickson SR, Hubalek Z: Migratory birds and spread of West Nile virus in the Western Hemisphere. Emerg Infect Dis 2000, 6:319-328.

42. 2010 West Nile Virus Human Infections in the United States (Reported to CDC as of December 14, 2010). [http://www.cdc.gov/ncidod/dvbid/ westnile/surv\&controlCaseCount10_detailed.htm]

43. Anuarios de Morbilidad. [http://www.dgepi.salud.gob.mx/anuario/html/ anuarios.html]

44. Rios-Ibarra C, Blitvich B, Farfan-Ale J, Ramos-Jimenez J, Muro-Escobedo S, Martínez-Rodriguez H, OrtizLópez R, Torres-López E, Rivas-Estilla A: Fatal human case of West Nile disease, Mexico, 2009. Emerg Infect Dis 2010 16:741-742.

45. Elizondo-Quiroga D, Davis CT, Fernandez-Salas I, Escobar-Lopez R, Olmos DV, Gastalum LCS, Acosta MA, Elizondo-Quiroga A, Gonzalez-Rojas II, Cordero JFC: West Nile virus isolation in human and mosquitoes, Mexico. Emerg Infect Dis 2005, 11:1449-1452.

46. Rodríguez ML, Rodriguez DR, Blitvich BJ, López MA, Fernández-Salas I, Jimenez JR, Farfán-Ale JA, Tamez RC, Longoria CM, Aguilar MI, RivasEstilla AM: Serologic surveillance for West Nile virus and other flaviviruses in febrile patients, encephalitic patients, and asymptomatic blood donors in northern Mexico. Vector Borne Zoonotic Dis 2010, 10:151-157.

47. Murgue $B$, Zeller $H$, Deubel V: The ecology and epidemiology of West Nile virus in Africa, Europe and Asia. Curr Top Microbiol Immunol 2002, 267:195-221.

48. Russell RC: Survival of insects in the wheel bays of a Boeing 747B aircraft on flights between tropical and temperate airports. Bull World Health Organ 1987, 65:659-662.
49. Aeropuerto Internacional de la Ciudad de Mexico. [http://www. aeropuertosmexico.com/content/view/446/521/]

50. Humeres SG, Almiron WR, Sabattini MS, Gardenal CN: Estimation of genetic divergence and gene flow between Culex pipiens and Culex quinquefasciatus (Diptera: Culicidae) in Argentina. Mem Inst Oswaldo Cruz 1998, 93:57-62.

51. Urbanelli S, Silvestrini F, Sabatinelli G, Raveloarifera F, Petrarca V, Bullini L Characterization of the Culex pipiens complex (Diptera: Culicidae) in Madagascar. J Med Entomol 1995, 32:778-786.

52. Vezzani D: Artificial container-breeding mosquitoes and cemeteries: A perfect match. Trop Med Int Health 2007, 12:299-313.

53. Huang S, Molaei G, Andreadis TG: Genetic insights into the population structure of Culex pipiens (Diptera: Culicidae) in the Northeastern United States by using microsatellite analysis. Am J Trop Med Hyg 2008, 79:518-527.

54. Tabachnick WJ, Powell JR: Genetic analysis of Culex pipiens populations in the Central Valley of California. Ann Entomol Soc Am 1983, 76:715-720.

55. Jakob WL, Taylor SA, Francy DB: Additional studies of male progeny of overwintering Culex pipiens complex mosquitoes from Memphis, Tennessee. Mosa Systemat 1980, 12:386-391.

56. Kothera L, Zimmerman EM, Richards CM, Savage HM: Microsatellite characterization of subspecies and their hybrids in Culex pipiens complex (Diptera: Culicidae) mosquitoes along a north-south transect in the central United States. J Med Entomol 2009, 46:236-248.

57. Reisen WK, Thiemann T, Barker CM, Lu H, Carroll B, Fang Y, Lothrop HD: Effects of warm winter temperature on the abundance and gonotrophic activity of Culex (Diptera: Culicidae) in California. J Med Entomol 2010, 47:230-237.

doi:10.1186/1756-3305-4-70

Cite this article as: Diaz-Badillo et al:: The distribution of potential West Nile virus vectors, Culex pipiens pipiens and Culex pipiens quinquefasciatus (Diptera: Culicidae), in Mexico City. Parasites \& Vectors 2011 4:70.

\section{Submit your next manuscript to BioMed Central and take full advantage of:}

- Convenient online submission

- Thorough peer review

- No space constraints or color figure charges

- Immediate publication on acceptance

- Inclusion in PubMed, CAS, Scopus and Google Scholar

- Research which is freely available for redistribution

Submit your manuscript at www.biomedcentral.com/submit
C) Biomed Central 